courses are planned, but the emphasis of the Unit will remain on research.

Bristol

The Bristol College of Science and Technology has established a Centre for Scientific and Technological Affairs. Since the Centre is primarily a research unit, its emphasis will at first depend on the availability of funds for designated pieces of research. Some work has already begun on a comparative study of scientific policies at different times and in various countries. Other projects are planned on the internal development of the sciences and their interrelation; on the external relations of the sciences with other disciplines and the influence of basic discoveries on technological and social change; and a statistical documentation of scientific growth in the modern period. In addition, Dr. Gerald Walters, who as head of the humanities department is initially organizing the Centre, plans a monthly seminar on the social, economic, political and philosophical aspects of scienee.

Manchester

'THE University' of Manchester has docided to concentrate on teaching, and is concerned to train what the director of the unit, Prof. F. R. Jevons, describes as "journalists, teachers, administrators, and decision makers who are well grounded in science on a broad front and yet can express themselves". There will be a small entry of students in October 1966 and possibly two dozen in 1967. Central concepts in the physical sciences will bo taught in conjunetion with economies, sociology, history and philosophy. According to Prof. Jevons, the depart. ment will be interested in questions such as the financing of science, the study of innovation, the possibility of applying cost-benefit analysis to scientific research, science and social policy, and the methods of teaching science. He intends to offer natural or geological sciences as alternatives to the physical sciences later on, if there is sufficient interest. He hopes "that the school will form an important link, the first of its kind, between the arts and the sciences".

Stirling

THE University of Stirling will also teach undergraduates but will have no students until October 1967. In what will be called the School of Technological Economics the intention is somehow to design a course to train industrial or public administrators, analysts of industrial operations and "the industrial researcher whose work depends on a correct appraisal of sociological and economic issues". To judge from what has been said so far, the School is aimed not so much at students interested in the social and political basis of science and science policies but rather in the application of science and scientific techniques, including games theory, linear programming and statistics, to industry.

Edinburgh

Ax Edinburgh the intention is to use the Science Studies Unit (under Dr. David Edge) to teach undergraduates and to conduct research "in those areas where scientific activities overlap with more general concerns of human society". There will be a short course of introductory lectures and seminars in September this year, and in the following academic year a one-year optional course for second- or third-year scienco undergraduates which, it is hoped, will soon become a two-year series. The teaching will be concerned with "the problems of economic growth, science policy decisions and sociological results of scientific advance".

\section{Dr. Van Zandt Williams}

THe death oceurred in London on May 13 of Dr. Van 7andt Williams, director of the American Institute of
Physics, at the age of fifty. He was making a short visit to discuss plans for a co-operative programme on physics abstracting and physies information services.

Dr. Williams was born in Providence, Rhode Island, gained a doctorate at Princeton University in 1941, and then entered the resoarch laboratories of American Cyanamid Corporation, where, with Dr. R. B. Barnes, he played a leading part in the development of spectroscopic techniques for use in industry. He was among the pioneers in the application of infra-red measurements to analysis, to problems of molecular structure, and in the differentiation of some of the newer chemical products such as synthetic rubbers. He soon became the assistant director of the physics division of the Cyanamid laboratories, but it was not surprising that shortly after the Second World War he joined the recently formed Porkin Elmer instrument company. There he guided the design and rapid manufacture of commercial infra-red spectrometers and other optical instruments, some of which have become classical and have acquired universal fame. He was director of research and sales, manager of the instrument division, and later executive vice-president of the company.

A year ago he became the director of the American Institute of Physics, and would shortly have completed his term of office as president of the American Optical Society, after leading the very successful meetings in Washington two months ago to celcbrate its fiftieth anniversary. He had also recently become the secretary of the committee for physics under the National Academy of Sciences, with the responsibility of maintaining relations with the International Union of Pure and Applied Chemistry.

Dr. Williams's death is a loss to American physics, to optics and spectroscopy, and to all who have international scientific co-operation at heart. Not only his colleagues in the United States, but also others the world over, and particularly in Europe, will miss his friendship, loyalty', sound counsel, wit and humanity, and share a great personal loss with his wife and two sons.

\section{Sociology of Engineering}

AN attempt to form a rounded picture of the character of the engineering profession in Britain is being made by the Council of Engineering Institutions with the financial backing of the Ministry of Technology. More than 25,000 chartered engineers are included in the sample being sent a detailed questionnaire intended to find out how engineers were trained to do their present jobs, and how they are rewarded. The survey will cover roughly 20 per cent of the membership of the thirteen engineering institutions affiliated to the Joint Council. The chairman of the Council, Sir Robert Wynne-Edwards, says in his introduction to the questionnaire that the results of the survey will be used to "help plan for the future by providing pointers towards better usage of engineering talent". Many working engineers will, no doubt, hope that the survey will also justify objectively the suspicion that engineers are paid too little.

The survey should provide sociological information of value outside engineering as such, partly because it has set out to define the levels of responsibility at which individual engineers function. To be sure, it will be a considerable test of character for a man to assign himself to category "A" by confessing that his work is "reviewed for accuracy and adequacy and for conformity with prescribed procedures", but the results could provide an. important insight into the sharing of responsibility in modern industry. It is therefore all tho more surprising, but entirely characteristic of the common conviction among engineers, that theirs is a job for men, that the questionnaire does not permit a woman to declare herself as such. Yet information about the employment of wormen engineers could have been particularly valuable in the recruitment of more. 